\title{
Burden of diabetes mellitus in patients with acromegaly treated with second-line pharmacotherapy in Spain
}

This article was published in the following Dove Press journal:

ClinicoEconomics and Outcomes Research

\author{
Laura Sánchez-Cenizo' \\ Javier Aller ${ }^{2}$ \\ José Manuel Martínez- \\ Sesmero ${ }^{3}$ \\ Nuria Mir ${ }^{1}$ \\ Carmen Peral ${ }^{1}$ \\ Darío Rubio-Rodríguez ${ }^{4}$ \\ Carlos Rubio-Terrés ${ }^{4}$ \\ 'Medical Department, Pfizer, S.L.U, \\ Madrid, Spain; ${ }^{2}$ Endocronology \\ Department, Hospital Universitario \\ Puerta De Hierro, Majadahonda, Madrid, \\ Spain; ${ }^{3}$ Hospital Pharmacy Department, \\ Hospital Clinico San Carlos, Madrid, \\ Spain; ${ }^{4}$ Pharmacoeconomics Department, \\ Health Value, Madrid, Spain
}

Objective: To evaluate the burden of diabetes mellitus (DM) in adult patients with acromegaly treated with second-line pharmacotherapy, from the perspective of the Spanish National Health System (NHS).

Methods: A Markov model was developed including three states: normal glucose metabolism, DM and death. The evolution of a hypothetical cohort of acromegaly patients requiring second-line pharmacological treatment (pegvisomant or pasireotide) after first generation somatostatin analogues therapy was analyzed. Direct healthcare costs regarding acromegaly management, diabetes management and drugs costs were obtained from Spanish sources. Transition probabilities between health states were obtained from published studies. Deterministic and probabilistic sensitivity analyses were undertaken.

Results: Compared to pasireotide, pegvisomant increased the likelihood of glucose normalization and reduced the likelihood of DM. Consequently, in a cohort of 1,000 patients with acromegaly, treatment with pegvisomant compared to pasireotide would prevent 243,413 and 453 cases of DM after 1, 2 and 5 years, respectively, and would reduce mortality by $0.1 \%$ after 5 years of treatment. This would result in 1 million euros savings for the NHS in 5 years. These health benefits would be obtained with savings of $€ 1,512, € 3,422$ and $€ 10,162$ per patient treated with pegvisomant, after 1, 2 and 5 years, respectively. After 5 years of treatment, the probability that pegvisomant generated savings versus pasireotide would be $65.3 \%$.

Conclusion: The favorable effects of pegvisomant on glucose metabolism would allow a considerable number of cases of DM to be avoided compared to pasireotide, resulting in savings for the NHS in Spain.

Keywords: diabetes mellitus, acromegaly, burden of illness, pegvisomant, pasireotide

\section{Introduction}

Acromegaly is a disease resulting from excessive production of growth hormone (GH) by the pituitary gland. It is caused in the vast majority of cases by a GHproducing adenoma and, in rare cases, by an ectopic secretion of growth hormonereleasing hormone $(\mathrm{GHRH}) .{ }^{1}$ Treatment goals in acromegaly include managing tumour growth, normalising high levels of $\mathrm{GH}$ and insulin-like growth factor 1 (IGF-1), managing disease symptoms, improving quality of life, managing comorbidities and preventing premature death. ${ }^{1}$ At present, there are three treatment modalities for acromegaly: surgery, pharmacological treatment and radiotherapy. Surgery is a first-line treatment in most patients. Pharmacotherapy is the treatment of choice in patients with significant surgical risk, or a complementary treatment
Correspondence: Laura Sánchez-Cenizo Pfizer, S.L.U., Avda. Europa, 20B. 20108Alcobendas, Madrid, Spain

Email Laura.Sanchez3@pfizer.com 
after surgery failures or until radiotherapy becomes effective. Currently, first generation somatostatin analogues (SA) (octreotide, lanreotide) are the treatment of choice when surgery is not curative. ${ }^{1}$ Pegvisomant is a GH analogue genetically modified to be a GH receptor antagonist approved in US as first line pharmacological treatment. It is indicated in Europe for the treatment of adult patients with acromegaly who have had an inadequate response to surgery or for whom surgery is not appropriate and who have had an inadequate response to SA or the SA was not tolerated (second-line pharmacological treatment). ${ }^{2}$ Pasireotide is a new (second generation) SA also approved in Europe as a second-line pharmacological treatment. ${ }^{3}$

Abnormal glucose metabolism is frequent in acromegaly patients at diagnosis, primarily due to a reduced insulin sensitivity mediated by the increased levels of GH and IGF1. In fact, diabetes mellitus (DM) is one of the comorbidities that most often contribute to the increased cardiovascular mortality in patients with acromegaly. ${ }^{4,5}$ Moreover, these abnormalities may increase or improve depending on the drug used to treat acromegaly. While SA appear to have a neutral effect on glucose metabolism, ${ }^{6}$ pasireotide has been found to cause, compared to classic SA, increased fasting plasma glucose (FPG) and glycated haemoglobin (HbAlc), thereby causing a higher incidence of hyperglycaemia adverse events that are drug-related, including DM. ${ }^{7-10}$ In contrast, pegvisomant has favourable effects on glucose metabolism, since it improves insulin sensitivity, decreases FPG, improves glucose tolerance and decreases HbAlc levels, even in patients with glucose intolerance or DM. ${ }^{11,12}$

Taking into account the different profile of pasireotide and pegvisomant on glucose metabolism, and the healthcare and economic impact of DM, a modelled analysis was proposed aimed to assess the healthcare and economic burden of DM in adult patients with acromegaly receiving second-line drug treatment, from the perspective of the Spanish National Health System (NHS).

\section{Methods}

\section{Summary of the economic model}

A Markov model ${ }^{13}$ was designed with three health states (normal glucose metabolism [NGM], DM and death) for 1, 2 and 5-year time horizons. Transition probabilities were obtained from published clinical and epidemiological studies (see Annual transition probabilities section). Unit costs of direct healthcare resources (expressed in euros [€] corresponding to 2018) were obtained from official
Spanish sources (see Costs of Markov states section). Deterministic and probabilistic analyses were performed. Results are presented: (i) as the evolution of the prevalence of DM in the cohort of adult patients with acromegaly treated with pegvisomant or pasireotide for a given time horizon, and (ii) as the incremental cost per patient treated with pegvisomant instead of pasireotide and the probability of pegvisomant generating savings.

\section{Patients}

The evolution of a hypothetical cohort of 1,000 patients with acromegaly requiring second-line pharmacological treatment (refractory to surgery and to treatment with the SA octreotide and/or lanreotide) was simulated. The prevalence of DM in the initial cohort was assumed to be $30.7 \%$ according to the analysis of the Spanish population in the ACROSTUDY observational study ${ }^{14}$ and in line with other Spanish data, such as the REA registry. ${ }^{15}$

\section{Markov model}

The model is shown in Figure 1. The cohort of patients may be treated with pegvisomant or pasireotide. In one case or another, the trees are identical from the Markov (M) node. Three states are considered: NGM, DM and death. Patients with NGM may stay in NGM or transition to DM or death. Patients with DM stay in DM or transition to NGM or death.

The state of DM is defined in the model as an abnormal baseline fasting plasma glucose (FPG) level $\geq 126 \mathrm{mg} / \mathrm{dl}$ or $\geq 200 \mathrm{mg} / \mathrm{dl} 2 \mathrm{hrs}$ after drinking a solution with $75 \mathrm{~g}$ of glucose. ${ }^{16}$

\section{Duration of cycles and time horizons}

The cohort transitions between the different states were analysed in one-year cycles.

The time horizons analysed were 1-, 2- and 5-years. These were determined considering that the vast majority of glucose abnormalities in patients with acromegaly treated with pasireotide would occur over the first two years of treatment. ${ }^{9,10}$ However, it is useful to perform longer-term simulations to have a better picture of the evolution of the cohort. ${ }^{13}$ Therefore, a 5-year time horizon was also considered. In this case, it was assumed that there were no transitions from the NGM state to DM neither in pasireotide nor in pegvisomant treatments from year 2 to year 5 .

\section{Annual transition probabilities}

All transition probabilities $\left(\mathrm{P}_{\mathrm{t}}\right)$ were calculated based on rates using the formula $\mathrm{Pt}=1-\mathrm{EXP}(-\mathrm{Rt})$, where $\mathrm{R}$ is the 


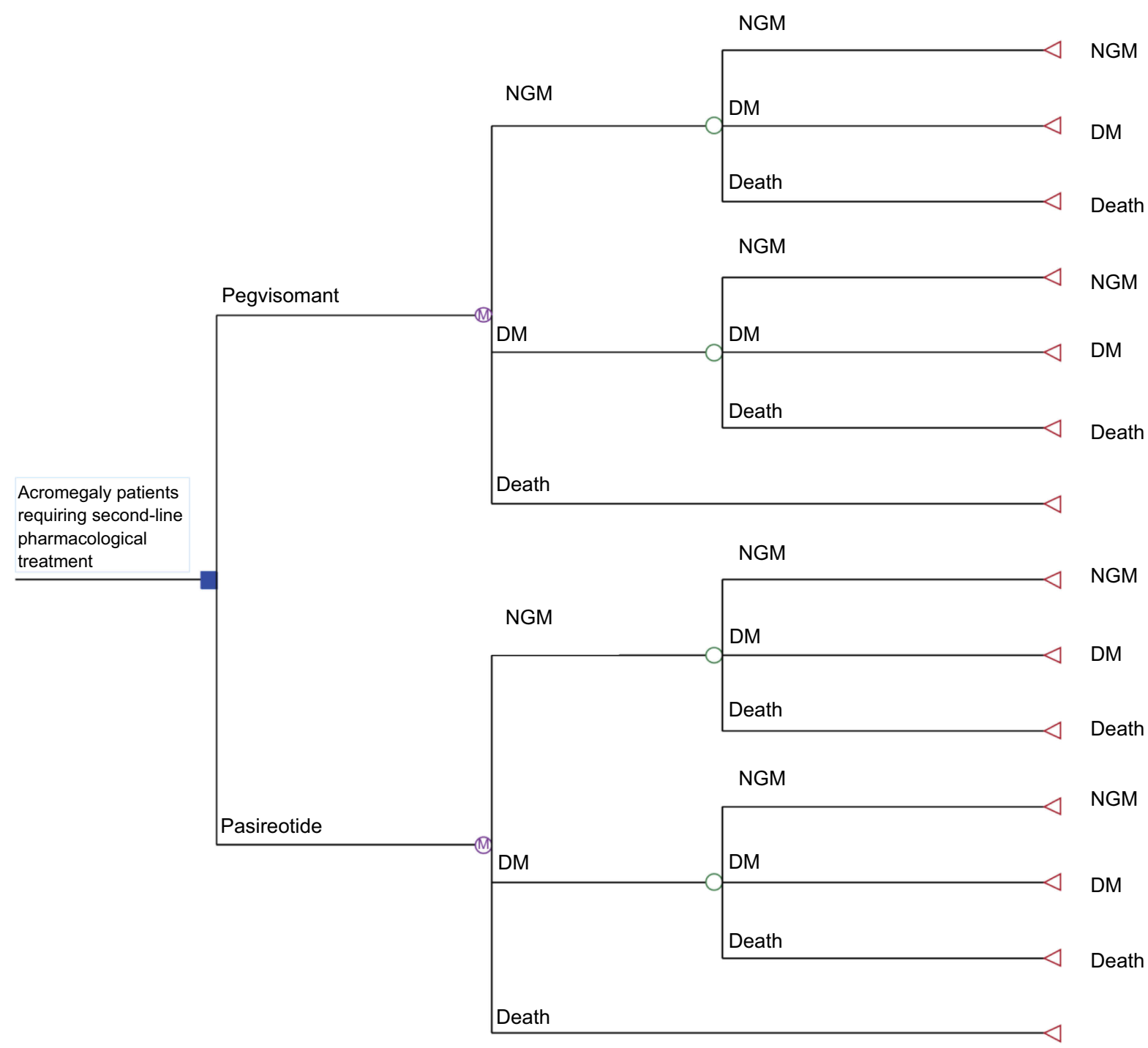

Figure I Markov model of diabetes mellitus in patients with acromegaly. Abbreviations: DM, diabetes mellitus; NGM, normal glucose metabolism.

rate and $\mathrm{t}$ is the time in which the rate was obtained. ${ }^{17}$ If $t$ was longer than 1 year, the Rt value was divided by the number of years of follow-up, ${ }^{17}$ since it was not possible to determine the annual distribution over the period due to a lack of disaggregated data. The mean values of the transition probabilities were estimated based on clinical studies, as indicated below. The minimum and maximum values of these probabilities were assumed to be $\pm 20 \%$ of the mean value. The standard deviation of the mean was calculated for a normal distribution.

The transition probabilities of the model are summarised in Table 1. ${ }^{9,18-22}$ Most probabilities were estimated based on observational safety studies, ${ }^{18,19,21}$ with the exception of the randomised clinical trial PAOLA, ${ }^{9}$ and the combined analysis of population studies FRESCO ${ }^{20}$ (Table 2).
The annual transition probability from NGM to DM in pegvisomant treated patients was obtained from the data of patients treated in monotherapy in ACROSTUDY observational study. ${ }^{18}$ In pasireotide treated patients, the mean value was obtained from ACCESS observational study ${ }^{19}$ and the extreme values from PAOLA clinical trial ${ }^{9}$ (Tables 1 and 2). The transition probabilities from NGM to death and from DM to death were calculated based on the Spanish FRESCO study, a combined analysis of 12 studies in diabetic patients without acromegaly ${ }^{20}$ (Tables 1 and 2). It was assumed that these annual probabilities of death are the same for both pegvisomant and pasireotide treated patients. The annual transition probability from DM to NGM in pegvisomant treated patients was calculated based on the German GPOS observational study ${ }^{21}$ (Tables 1 and 2). No transitions of this 


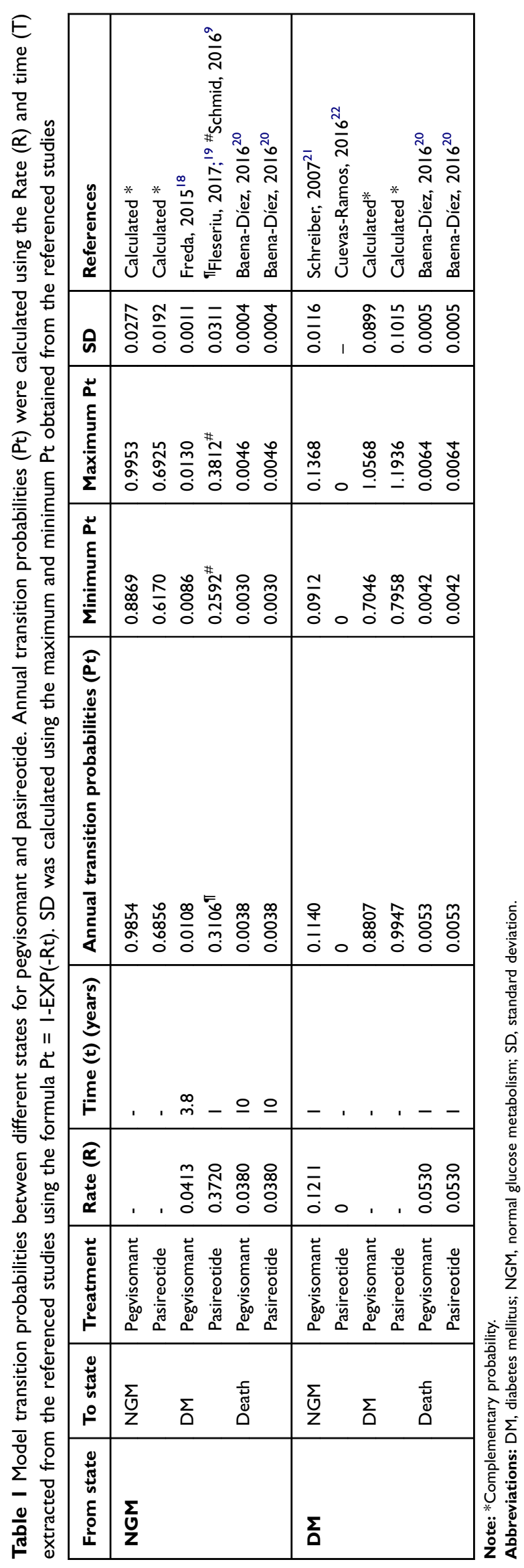




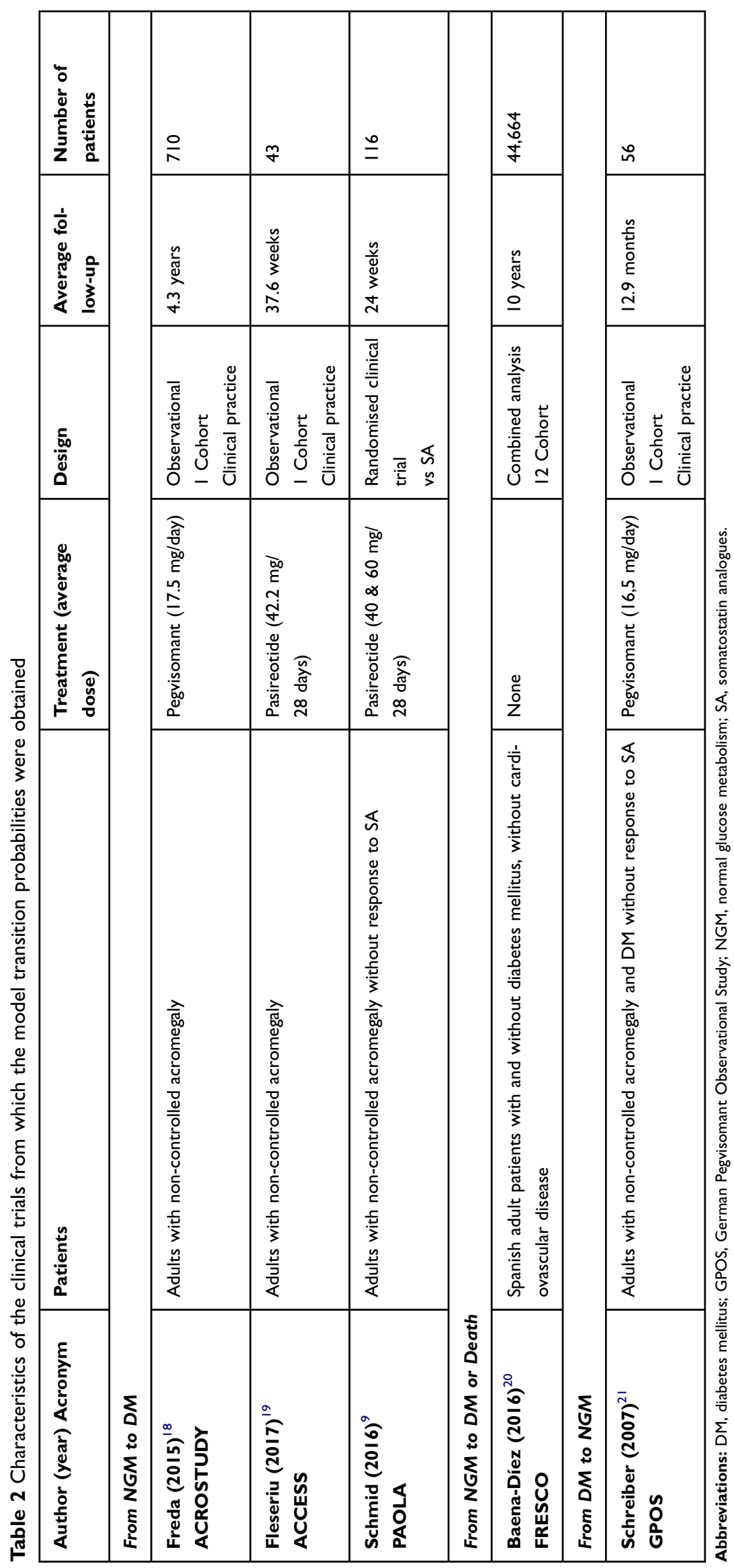


kind have been described in patients treated with pasireotide, ${ }^{22}$ so a zero probability was assigned (Tables 1 and 2). All other transition probabilities were calculated as complementary to the above mentioned probabilities (Table 1).

\section{Costs of Markov states}

Three direct healthcare costs were taken into account: (i) the annual cost of treatment with pegvisomant or pasireotide; (ii) the annual cost of clinical management of acromegaly (excluding the cost of acromegaly-specific treatment); and (iii) the annual cost of clinical management of DM. The state of death was considered cost-free. All costs were updated to 2018 (Table 3).

The estimated annual cost of clinical management of acromegaly was obtained from a Spanish study by Roset et al, ${ }^{23}$ considering costs of medical visits, examinations and hospitalizations and excluding acromegaly treatment costs (drugs, surgery and radiotherapy). The average annual cost per patient with DM was calculated based on a review of seven Spanish studies by the Spanish Agency for Healthcare Technology Assessment (AETS) ${ }^{24}$ and a recently published Spanish study. ${ }^{25}$ This cost comprises only direct healthcare costs associated to DM. The minimum and maximum costs of both Markov states were estimated at $\pm 20 \%$ of the mean value obtained from the literature. The standard deviations used for the probabilistic analysis were calculated for normal distributions.

Pegvisomant is available in five different dose presentations $(10,15,20,25$ and $30 \mathrm{mg})$. The annual cost of a patient treated with pegvisomant was calculated considering a mean daily dose of $15 \mathrm{mg} /$ day, according to the mean dose used in Spanish ACROSTUDY patients, ${ }^{14}$ where this drug was administered over a mean period of 6.7 \pm 2.1 years (Table 3). Minimum and maximum annual costs were calculated considering $10 \mathrm{mg} /$ day and $25 \mathrm{mg} /$ day doses, respectively, in line with the mean dose and standard deviation in ACROSTUDY ${ }^{14}$ (Table 3). The annual cost was calculated based on an assumption of 365 days of treatment. A deduction of $7.5 \%$ (25 and $30 \mathrm{mg}$ presentations $)$ or $15 \%(10,15$ and $20 \mathrm{mg}$ presentations) was applied to the ex-factory price in accordance with current regulations. ${ }^{26}$

Due to the lack of published data on the mean dose of pasireotide in clinical practice, the annual cost of pasireotide was calculated assuming that $50.6 \%$ of patients initially treated with the starting dose of $40 \mathrm{mg} / 28$ days had their dose increased to $60 \mathrm{mg} / 28$ days during a year of treatment, as observed in a pasireotide pivotal study. ${ }^{8}$ Therefore, the mean dose of pasireotide used in the model was $50.1 \mathrm{mg} / 28$ days (Table 3). Minimum and maximum annual costs were calculated considering the $40 \mathrm{mg} / 28$ days and $60 \mathrm{mg} / 28$ days doses, respectively, in line with the summary of product characteristics. ${ }^{3}$ Since the cost per mg of pasireotide differs between its 40-mg and $60-\mathrm{mg}$ presentations, both costs per $\mathrm{mg}$ were weighted by the use of each presentation to calculate the mean cost of treatment with pasireotide. Minimum and maximum costs were calculated using the price of $40 \mathrm{mg}$ and $60 \mathrm{mg}$ presentations respectively. The annual cost was also calculated based on an assumption 365 days of treatment. A deduction of $4 \%$ was applied to the ex-factory price in accordance with current regulations. ${ }^{26}$

\section{Analyses performed and presentation of results}

A deterministic analysis with a fixed result, using the mean values of all variables (probabilities and costs) was performed. In addition, a probabilistic analysis in which the result differs each time the analysis is repeated, using random values for each variable, was performed. ${ }^{13}$ The probabilistic analysis was performed using a second-order Monte Carlo simulation (taking into account both individual variability and the uncertainty of the model's parameters [probabilities and costs]). ${ }^{13}$ As recommended, the probabilities were adjusted to beta distributions and the costs were adjusted to gamma distributions. ${ }^{13,27}$

Results are presented as the evolution of the prevalence of DM in the cohort of adult patients with acromegaly treated with pegvisomant or pasireotide and as the incremental cost per patient treated with pegvisomant instead of pasireotide and the probability of pegvisomant generating savings.

In addition, three further deterministic sensitivity analyses were performed: (i) considering a DM initial prevalence of $28.0 \%$, based on the minimum prevalence reported in other European patients with acromegaly, corresponding to a cohort of Belgian patients; ${ }^{28}$ (ii) considering an initial DM prevalence of $52.5 \%$, based on the maximum prevalence reported in other European patients, corresponding to a cohort of Dutch patients; ${ }^{29}$ and (iii) assuming a possible scenario in which pasireotide-treated patients without normalization of IGF-1 after 1 year of treatment $(74 \% \text { of patients in PAOLA clinical trial) })^{7,22}$ change to pegvisomant in year 2 and, therefore, the cost 


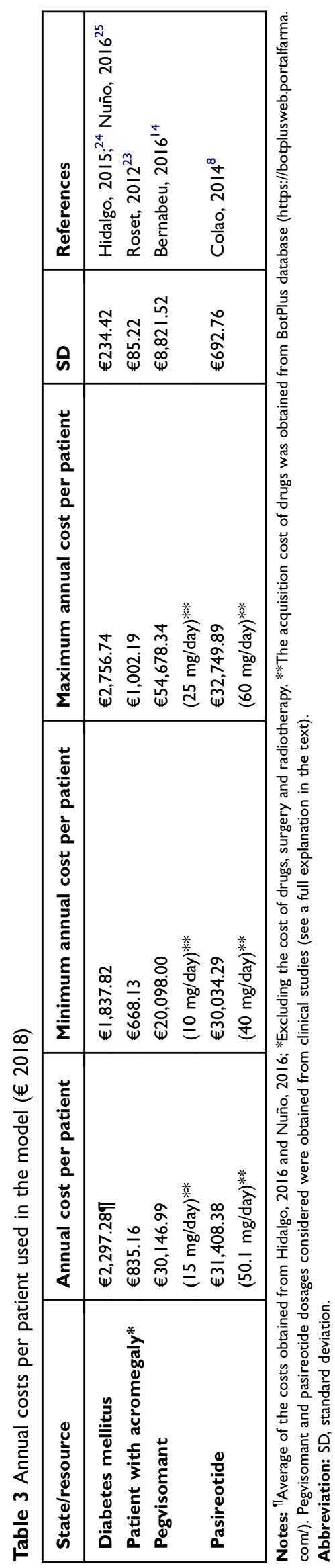

of pegvisomant is attributed to pasireotide from year 2 onwards.

\section{Results}

\section{Healthcare impact}

The deterministic analysis showed an absolute reduction in the number of cases of DM by $24.3 \%$ in year $1,41.3 \%$ in year 2 and $45.3 \%$ in year 5 in patients with acromegaly treated with pegvisomant, compared to pasireotide (Figure 2). In addition, the expected number of mortality cases was slightly reduced by $0.1 \%$ in year 2 and 5 (Figure 2). Therefore, in a cohort of 1,000 patients with acromegaly, treatment with pegvisomant would prevent 243, 413 and 453 cases of DM after 1, 2 and 5 years, respectively, compared to pasireotide (Table 4).

\section{Economic impact}

Taking into account the annual cost of the patient with DM (Table 3), it is estimated that, in a cohort of 1,000 patients with acromegaly, prevented cases of DM by pegvisomant treatment would result in savings ranging from $€ 558,239$ in year 1 to $€ 1,040,668$ in year 5 (Table 4).

For a 1-year time horizon, treatment with pegvisomant would generate savings of $4.6 \%(-€ 1,512)$ per patient (Table 5). Assuming a 2-year follow-up period, the savings would be $5.3 \%(-€ 3,422)$ per patient. For the 5 -year time horizon, the additional savings would be $6.5 \%(-€ 10,162)$ per patient (Table 5). According to the probabilistic analysis, the probabilities of savings with pegvisomant versus
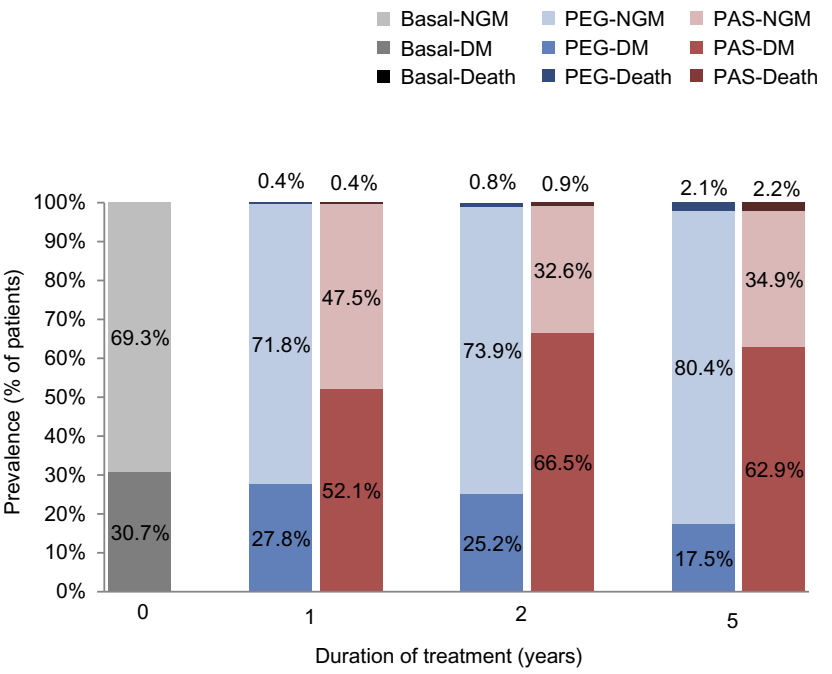

Figure 2 Evolution of glucose alterations in the cohort of patients with acromegaly modelled. Prevalence of normal glucose metabolism (NGM), diabetes mellitus (DM) and death at basal (grey) I, 2 and 5 years of pegvisomant (blue) or pasireotide (red) treatment. 
Table 4 Prevented cases of diabetes mellitus and savings derived. Number of avoided cases of diabetes mellitus and estimation of the consequent savings in a cohort of I,000 patients with acromegaly treated with pegvisomant vs pasireotide for I, 2 and 5 years

\begin{tabular}{|l|l|l|l|l|}
\hline $\begin{array}{l}\text { Time horizon } \\
\text { (years) }\end{array}$ & $\begin{array}{l}\text { Cases of DM with } \\
\text { PEG }\end{array}$ & $\begin{array}{l}\text { Cases of DM with } \\
\text { PAS }\end{array}$ & $\begin{array}{l}\text { Avoided cases of DM with PEG } \\
\text { vs PAS }\end{array}$ & $\begin{array}{l}\text { Savings due to avoided cases } \\
\text { of DM }\end{array}$ \\
\hline $\mathbf{I}$ & 278 & -243 & $-€ 558,239$ \\
$\mathbf{2}$ & 252 & 521 & -413 & $-€ 948,777$ \\
$\mathbf{5}$ & 175 & 665 & -453 & $-€ 1,040,668$ \\
\hline
\end{tabular}

Abbreviations: DM, diabetes mellitus; PEG, pegvisomant; PAS, pasireotide.

pasireotide would be around $65.3 \%$ for the 5 -year time horizon (Table 5).

According to the results of the sensitivity analysis, assuming a prevalence of DM of $28.0 \%$, the savings with pegvisomant versus pasireotide would be $5.5 \%$ ( $€ 8,367)$ per patient for the 5 -year time horizon. Assuming an initial prevalence of DM of $52.5 \%$, the savings with pegvisomant versus pasireotide would be $5.4 \%(€ 8,334)$ per patient for the 5-year time horizon.

The results of the sensitivity analysis, considering the rescue treatment with pegvisomant in patients with an inadequate response to pasireotide in year 1 , show that the savings per patient would decrease in year 2 from $€ 3,422$ (base case) to $€ 2,520$ per patient. The probability of pegvisomant generating savings would decrease from $64.9 \%$ to $57.7 \%$.

\section{Discussion}

Pegvisomant and pasireotide are two second-line pharmacological treatments for acromegaly with different mechanisms of action and different efficacy and safety profiles. When choosing one treatment or the other it is important to consider patient characteristics and disease activity, but also drug characteristics and its suitability for the patient. It is also important to remember that the acromegaly therapy should be tailored on patients' characteristics, including glucose and tumour status.

Pasireotide shows a higher incidence of hyperglycaemia-related adverse events, including DM, compared to other SA. In fact, this is one of the most common reasons of treatment discontinuation ${ }^{7-10,19}$ although an adequate treatment of glucose abnormalities could minimize the potential impact on morbidity or mortality. This hyperglycaemic effect seems to be more remarkable in patients with a pre-existent impaired glucose homeostasis. ${ }^{9}$ Due to its greater affinity for SSTR5 receptors over SSTR2 receptors, pasireotide causes a potent suppression of insulin and incretin secretion, with minimal suppression of glucagon secretion and no impact on insulin sensitivity; inducing an increase in glucose levels. ${ }^{30}$ Pegvisomant improves insulin sensitivity by blocking GH effects without directly affecting the synthesis of insulin or other pancreatic peptides, ${ }^{11,31}$ resulting in a decrease in FPG and HbA1c levels. In fact, ACROSTUDY patients with DM treated with pegvisomant showed a significant mean reduction in FPG compared to baseline in years 1 and $4 .{ }^{14}$

Management of acromegaly should be focused not only on biochemical (normalisation of GH and IGF-1 levels) and tumour size control, but also on the control of associated comorbidities such as diabetes. ${ }^{32}$ In fact, diabetes contributes to the increased mortality in patients with acromegaly and correlates with other cardiovascular risk factors. ${ }^{33,34}$ In addition, diabetes has a significant economic impact, a variable to be taken into account when selecting a treatment for acromegaly.

According to the results of this analysis, second-line treatment of adult acromegaly patients with pegvisomant

Table 5 Analysis of differential cost per patient. Cost differences per patient treated with pegvisomant vs pasireotide and probability of savings with pegvisomant at I, 2 and 5 years of treatment

\begin{tabular}{|l|l|l|l|l|l|}
\hline $\begin{array}{l}\text { Time horizon } \\
\text { (years) }\end{array}$ & Cost per patient with PEG & Cost per patient with PAS & $\begin{array}{l}\text { Savings per } \\
\text { patient treated } \\
\text { with PEG }\end{array}$ & Probability of savings with PEG \\
\cline { 3 - 5 } & & & $\mathbf{( € )}$ & $\mathbf{( \% )}$ & \\
\hline $\mathbf{I}$ & $€ 3 I, 129$ & $€ 32,641$ & $-€ I, 5 / 2$ & $-4.6 \%$ & $60.2 \%$ \\
$\mathbf{2}$ & $€ 6 I, 167$ & $€ 64,589$ & $-€ 3,422$ & $-5.3 \%$ & $64.9 \%$ \\
$\mathbf{5}$ & $€ \mid 45,174$ & $€ \mid 55,336$ & $-€ 10,162$ & $-6.5 \%$ & $65.3 \%$ \\
\hline
\end{tabular}

Abbreviations: PEG, pegvisomant; PAS, pasireotide. 
considerably reduces the incidence of diabetes mellitus compared to pasireotide (by $24.3 \%$ in year $1,41.3 \%$ in year 2 and $45.3 \%$ in year 5). This favourable healthcare impact would yield savings due to a reduction in diabetes associated cost. In a cohort of 1,000 patients with acromegaly, pegvisomant would prevent 243, 413 and 453 cases of DM with savings of $4.6 \%, 5.3 \%$ and $6.5 \%$ in total treatment cost after 1, 2 and 5 years of follow-up, respectively. These results could be useful for clinical decisionmaking in patients with acromegaly, together with the differential effect of both drugs on IGF-1 normalization. ${ }^{7}$

The probabilistic analyses confirm the robustness of the proposed economic model, showing that the probabilities of savings using pegvisomant range from $60.2 \%$ to $65.3 \%$. In the univariate deterministic sensitivity analysis, including the rescue treatment with pegvisomant in year 2 for patients with an inadequate response to pasireotide at year 1, pegvisomant would still generate savings $(€ 2,520$ per patient), although at a lower probability (57.7\%).

This economic model has, however, several limitations. Firstly, it has the limitations inherent to a theoretical model, which, nevertheless, is a useful simulation of clinical reality. ${ }^{35}$ Secondly, due to the absence of clinical studies directly comparing the two treatments, most of the model's probabilities were taken from three observational studies, ${ }^{18,19,21}$ one randomised clinical trial of pasireotide versus $\mathrm{SA}^{9}$ and one combined analysis of Spanish population studies ${ }^{20}$ with different population sizes and duration of treatment (Table 2). The lack of real-world data on pasireotide drug usage in Spain is also a limitation. Thirdly, this analysis is specific to Spain NHS costs and may not apply to other countries. Fourth, this model does not take into account other possible costs related to acromegaly and diabetes, such as costs due to loss of productivity and other indirect costs, or the impact on the patient's quality of life. Fifth, there is no analysis of the costs of combined therapy using first-generation $\mathrm{SA}+\mathrm{GH}$ receptor antagonist, taking into account that half of the Spanish patients of the ACROSTUDY study ${ }^{14}$ were treated with monotherapy. Finally, the economic model only includes diabetes-related costs. However, the two drugs compared differ in many other aspects, ie the liver enzyme abnormalities under pegvisomant, the different need of MRI follow up given the tumour reducing effect of parireotide, and the absence of such tumour reduction during pegvisomant treatment.
Recently, two systematic reviews have been published on the cost-effectiveness of pharmacological treatments for patients with acromegaly. ${ }^{36,37}$ Neither the review of Leonart et $\mathrm{al}^{36}$ nor that of Orlewska et al, ${ }^{37}$ identified any comparative economic analysis of pegvisomant and pasireotide that took into account the specific impact of diabetes mellitus as an important cost driver in the acromegaly management.

In summary, according to this model, the favourable effects of pegvisomant on glucose metabolism would enable the prevention of a considerable number of cases of DM compared to pasireotide, with savings up to $6.5 \%$ of the total treatment cost, in Spain.

\section{Acknowledgments}

The abstract of this paper was presented at the ISPOR 20th Annual European Congress, 2018, Glasgow, as a poster presentation with interim findings. The poster's abstract was published in Value in Health. 2017;20: A553 (https:// www.valueinhealthjournal.com/article/S1098-3015(17) 31210-X/pdf).

\section{Authors contributions}

C Rubio-Terrés and D Rubio-Rodríguez developed the economic model. C Peral, L Sánchez-Cenizo, N Mir, J Aller and JM Martínez-Sesmero, reviewed in depth the economic model. C Rubio-Terrés, D Rubio-Rodríguez, $\mathrm{C}$ Peral and L Sanchez-Cenizo wrote the first and subsequent versions of the manuscript. All authors contributed to the fruitful discussion of the results and to the review of the different versions of the manuscript. All authors read, edited and approved the final manuscript. C Rubio-Terrés is the guarantor for the overall content of the paper.

\section{Disclosure}

This analysis was sponsored by Pfizer (Spain). C RubioTerrés and D Rubio-Rodríguez are employees of Health Value, who received an honorarium from Pfizer (Spain) in connection with the development of this manuscript. Medical writing support was provided by C Rubio-Terrés and D Rubio-Rodríguez at Health Value and was funded by Pfizer (Spain). C Peral, L Sanchez-Cenizo and N Mir, are employees of Pfizer (Spain). J Aller has received speaker honoraria from Pfizer (Spain) and Novartis. The authors report no other conflicts of interest in this work. 


\section{References}

1. Cordido F, García Arnés JA, Marazuela Aspiroz M, Torres Vela E; grupo de Neuroendocrinología de la Sociedad Española de Endocrinología y Nutrición. Practical guidelines for diagnosis and treatment of acromegaly. Grupo de Neuroendocrinología de la Sociedad Española de Endocrinología y Nutrición. Endocrinol Nutr. 2013;60(8):457.e1-457.e15.

2. Somavert $10 \mathrm{mg}$ polvo y disolvente para solución inyectable. Ficha técnica o Resumen de las características del producto. Available from: http://www.ema.europa.eu/docs/es_ES/document_library/ EPAR_-_Product_Information/human/000409/WC500054629.pdf. Accessed March 28, 2017.

3. Signifor $40 \mathrm{mg}, 1$ vial polvo +1 jeringa disolvente para solución inyectable. Ficha técnica o Resumen de las características del producto. Available from: https://botplusweb.portalfarma.com/ Documentos/2016/12/13/105330.pdf. Accessed March 28, 2017.

4. Pivonello R, Auriemma RS, Grasso LF, et al. Complications of acromegaly: cardiovascular, respiratory and metabolic comorbidities. Pituitary. 2017;20:46-62. doi:10.1007/s11102-017-0797-7

5. Ferraù F, Albani A, Ciresi A, Giordano C, Cannavò S. Diabetes secondary to acromegaly: physiopathology, clinical features and effects of treatment. Front Endocrinol (Lausanne). 2018;6(9):358. doi:10.3389/fendo.2018.00358

6. Mazziotti G, Floriani I, Bonadonna S, Torri V, Chanson P, Giustina A. Effects of somatostatin analogs on glucose homeostasis: a metaanalysis of acromegaly studies. J Clin Endocrinol Metab. 2009;94:1500-1508. doi:10.1210/jc.2008-2332

7. Gadelha MR, Bronstein MD, T B, et al; Pasireotide C2402 Study Group. Pasireotide versus continued treatment with octreotide or lanreotide in patients with inadequately controlled acromegaly (PAOLA): a randomised, phase 3 trial. Lancet Diabetes Endocrinol. 2;2014:875-884. doi:10.1016/S2213-8587(14)70169-X

8. Colao A, Bronstein MD, Freda P, et al; Pasireotide C2305 Study Group. Pasireotide versus octreotide in acromegaly: a head-to-head superiority study. J Clin Endocrinol Metab. 99;2014:791-799. doi: $10.1210 /$ jc. $2013-2480$

9. Schmid HA, Brue T, Colao A, et al. Effect of pasireotide on glucoseand growth hormone-related biomarkers in patients with inadequately controlled acromegaly. Endocrine. 2016;53:210-219. doi:10.1007/ s12020-016-0895-8

10. Sheppard M, Bronstein MD, Freda P, et al. Pasireotide LAR maintains inhibition of GH and IGF-1 in patients with acromegaly for up to 25 months: results from the blinded extension phase of a randomized, double-blind, multicenter, Phase III study. Pituitary. 2015;18:385-394. doi:10.1007/s11102-014-0585-6

11. Barkan AL, Burman P, Clemmons DR, et al. Glucose homeostasis and safety in patients with acromegaly converted from long-acting octreotide to pegvisomant. J Clin Endocrinol Metab. 2005;90:56845691. doi:10.1210/jc.2005-0331

12. Giustina A, Ambrosio MR, Beck Peccoz P, et al. Use of Pegvisomant in acromegaly. An Italian Society of Endocrinology guideline. J Endocrinol Invest. 2014;37:1017-1030. doi:10.1007/s40618-014-0146-x

13. Gray AM, Clarke PM, Wolstenholme JL, Wordsworth S. Applied Methods of Cost-effectiveness Analysis in Health Care. Oxford: Oxford University Press; 2012.

14. Bernabeu I, Pico A, Venegas E, et al; Spanish ACROSTUDY Group. Safety of long-term treatment with Pegvisomant: analysis of Spanish patients included in global ACROSTUDY. Pituitary. 19;2016:127137. doi:10.1007/s11102-015-0691-0

15. Mestron A, Webb SM, Astorga R, et al. Epidemiology, clinical characteristics, outcome, morbidity and mortality in acromegaly based on the Spanish Acromegaly Registry (Registro Espanol de Acromegalia, REA). Eur J Endocrinol. 2004;151:439-446.
16. WHO. Qué es la diabetes. Available from: http://www.who.int/dia betes/action_online/basics/es/index1.html. Accessed March 28, 2017.

17. Petitti DB. Meta-Analysis, Decision Analysis, and Cost-Effectiveness Analysis. New York: Oxford University Press; 1994.

18. Freda PU, Gordon MB, Kelepouris N, Jonsson P, KoltowskaHaggstrom M, van der Lely AJ. Long-term treatment with pegvisomant as monotherapy in patients with acromegaly: experience from ACROSTUDY. Endocr Pract. 2015;21:264-274. doi:10.4158/ EP14330.OR

19. Fleseriu M, Rusch E, Geer EB; ACCESS Study Investigators. Safety and tolerability of pasireotide long-acting release in acromegalyresults from the acromegaly, open-label, multicenter, safety monitoring program for treating patients who have a need to receive medical therapy (ACCESS) study. Endocrine. 2017;55:247-255. doi:10.1007/ s12020-016-1182-4

20. Baena-Díez JM, Peñafiel J, Subirana I, et al; FRESCO Investigators. Risk of cause-specific death in individuals with diabetes: a competing risks analysis. Diabetes Care. 39;2016:1987-1995. doi:10.2337/ dc16-0614

21. Schreiber I, Buchfelder M, Droste M, et al; German Pegvisomant Investigators. Treatment of acromegaly with the GH receptor antagonist pegvisomant in clinical practice: safety and efficacy evaluation from the German Pegvisomant Observational Study. Eur $J$ Endocrinol. 2007;156:75-82. doi:10.1530/eje.1.02312

22. Cuevas-Ramos D, Fleseriu M. Pasireotide: a novel treatment for patients with acromegaly. Drug Des Devel Ther. 2016;10:227-239. doi:10.2147/DDDT.S77999

23. Roset M, Merino-Montero S, Luque-Ramírez M, et al; Spanish group of the OASIS study. Cost of clinical management of acromegaly in Spain. Clin Drug Investig. 32;2012:235-245. doi:10.2165/11599680000000000-00000

24. Hidalgo A, Oliva J, Rubio M, Zozaya N, Villoro R, García S. Estudios de coste de la diabetes tipo 2: una revisión de la literatura. Madrid: Agencia de Evaluación de Tecnologías Sanitarias - Instituto de Salud Carlos III, Febrero de; 2015.

25. Nuño-Solinís R, Alonso-Morán E, Arteagoitis JM, Ezkurra P, Orueta JF, Gaztambide S. Costes sanitarios de la población con diabetes mellitus tipo 2 en el País Vasco (España). Endocrinolo Nutric. 2016;63:543-550. doi:10.1016/j.endonu.2016.08.003

26. Listado de medicamentos afectados por las deducciones del real Decreto-Ley 8/2010 - Agosto 2018. Available from: https://www. mscbs.gob.es/profesionales/farmacia/pdf/DeduccionesAgosto2018. pdf. Accessed August 1, 2018.

27. Briggs A, Claxton K, Sculpher M. Decision Modelling for Health Economic Evaluation. Oxford: Oxford University Press; 2006.

28. Alexopoulou O, Bex M, Kamenicky P, Mvoula AB, Chanson P, Maiter D. Prevalence and risk factors of impaired glucose tolerance and diabetes mellitus at diagnosis of acromegaly: a study in 148 patients. Pituitary. 2014;17:81-89. doi:10.1007/s11102-013-0471-7

29. Dreval AV, Trigolosova IV, Misnikova IV, et al. Prevalence of diabetes mellitus in patients with acromegaly. Endocr Connect. 2014;3:93-98. doi:10.1530/EC-14-0021

30. Schmid HA, Brueggen J. Effects of somatostatin analogues on glucose homeostasis in rats. J Endocrinol. 2012;212:49-60. doi:10.1530/ JOE-11-0224

31. Droste M, Domberg J, Buchfelder M, et al. Therapy of acromegalic patients exacerbated by concomitant type 2 diabetes requires higher pegvisomant doses to normalise IGF1 levels. Eur J Endocrinol. 2014;171:59-68. doi:10.1530/EJE-13-0438

32. Katznelson L, Laws ER Jr, Melmed S, et al; Endocrine Society. Acromegaly: an endocrine society clinical practice guideline. J Clin Endocrinol Metab. 2014;99:3933-3951. doi:10.1210/jc.2014-2700

33. Rajasoorya C, Holdaway IM, Wrightson P, Scott DJ, Ibbertson HK. Determinants of clinical outcome and survival in acromegaly. Clin Endocrinol (Oxf). 1994;41:95-102. 
34. Colao A, Baldelli R, Marzullo P, et al. Systemic hypertension and impaired glucose tolerance are independently correlated to the severity of the acromegalic cardiomyopathy. J Clin Endocrinol Metab. 2000;85:193-199. doi:10.1210/jcem.85.1.6318

35. Rubio-Terrés C, Sacristán JA, Badía X, Cobo E, Alonso FG; por el Grupo ECOMED. Métodos utilizados para realizar evaluaciones económicas de intervenciones sanitarias. Med Clín (Barc). 2004;122:578-583. (b).
36. Leonart LP, Borba HHL, Ferreira VL, Riveros BS, Pontarolo R. Costeffectiveness of acromegaly treatments: a systematic review. Pituitary. 2018;21:642-652. doi:10.1007/s11102-018-0908-0

37. Orlewska E, Stępień R, Orlewska K. Cost-effectiveness of somatostatin analogues in the treatment of acromegaly. Expert Rev Pharmacoecon Outcomes Res. 2018;3:1-11.

\section{Publish your work in this journal}

ClinicoEconomics and Outcomes Research is an international, peerreviewed open-access journal focusing on Health Technology Assessment, Pharmacoeconomics and Outcomes Research in the area of diagnosis, medical devices, and clinical, surgical and pharmacological intervention. The economic impact of health policy and health systems organization also constitute important areas of coverage. The manuscript management system is completely online and includes a very quick and fair peer-review system, which is all easy to use. Visit http://www.dovepress.com/testimonials.php to read real quotes from published authors. 